\title{
A meta-analysis of the use of $4 \%$ icodextrin solution to prevent adhesion formation after gynaecological surgery
}

\author{
Fiona L. Mackie • Sofia Dias • Andrew Watson • Gaity Ahmad
}

Received: 12 June 2012 / Accepted: 19 July 2012 /Published online: 1 September 2012

(C) Springer-Verlag 2012

\begin{abstract}
Post-surgical adhesions are common and can cause substantial co-morbidity. The aim of this review was to investigate the efficacy of $4 \%$ icodextrin solution, a widely used adhesion prevention agent, in gynaecological surgery. Randomised-controlled trials comparing the use of $4 \%$ icodextrin solution vs. Ringer's-lactated saline (control) in women of any age undergoing fertility-conserving surgery either by laparoscopy or laparotomy were searched and meta-analysis performed. Compared to Ringer's-lactated saline, there was no significant difference in the number of patients free from de novo adhesions at second-look laparoscopy (SLL) (odds ratio, $1.21[0.76,1.93]$ ), the adhesion score reduction at SLL (mean difference (MD), $0.71[-0.66$, $2.08]$ ), the percentage reduction in adhesion extent (MD, $5.47[-4.18,15.12])$ or severity (MD, $13.49[-23.78$,
\end{abstract}

\section{F. L. Mackie}

Education and Research Centre, Pennine Acute Trust, Royal Oldham Hospital,

Rochdale Road,

Oldham OL12JH, UK

\section{S. Dias}

School of Social and Community Medicine,

University of Bristol,

Canynge Hall, 39 Whatley Road,

Bristol BS8 2PS, UK

\section{A. Watson}

FRCOG, Department of Obstetrics and Gynaecology,

Tameside General Hospital,

Fountain Street, Ashton Under Lyne,

Lancashire OL6 9RW, UK

G. Ahmad ( $\square)$

MRCOG, Department of Obstetrics and Gynaecology,

Pennine Acute Trust, Royal Oldham Hospital,

Rochdale Road,

Oldham OL12JH, UK

e-mail: Gaity.ahmad@pat.nhs.uk
50.75]). The included studies reported the effect of $4 \%$ icodextrin in different ways thus limiting meta-analysis. This is the first meta-analysis of icodextrin and the lack of evidence found to support the use of icodextrin suggests further research is required which should be presented in a uniform manner.

Keywords Adhesions · Gynaecological · Icodextrin · Adept $\cdot$ Meta-analysis

\section{Background}

Adhesions are fibrin bands which develop due to aberrant healing of the peritoneum [3]. Damage to the peritoneum results in an inflammatory response which activates the coagulation cascade and a fibrin plug then forms over the damaged mesothelial tissue. Normally, the fibrin plug is broken down, revealing regenerated peritoneum. However, in adhesion formation, less fibrinolysis occurs and a fibrin matrix develops. The presence of adhesions may have no consequence but can cause infertility, pain, bowel obstruction and their presence is associated with increased risks of complications from further surgery.

Pelvic adhesions are the commonest complication of gynaecological surgery and form in 50-100 \% of women who undergo gynaecological surgery [2]. Other causes of adhesions include: infection, particularly pelvic inflammatory disease, endometriosis, and ischaemia [2]. Five percent of patients are re-admitted with problems related to adhesions [2]. These consequences can have a negative impact on a patient's quality of life and may necessitate further surgery.

Adhesions also have considerable public health and financial implications. It is estimated that the direct cost of readmissions related to adhesions in the first year after lower 
abdominal surgery is $£ 24.2$ million, which increases to $£ 95.2$ million 10 years after the initial surgery [6].

Adhesiolysis although accepted in clinical practice is still controversial [2]. Thus, the focus of adhesion management is prevention. There are a variety of adhesion prevention agents available which can be divided into solid mechanical barriers and fluid agents. Icodextrin (4\%) solution (Adept, Baxter, Berkshire, UK) is widely used as an adhesion prevention agent as it is easy to use and store, and is relatively cheap compared to other adhesion prevention agents. It is a non-viscous, iso-osmotic fluid which contains icodextrin - a glucose polymer (molecular weight, $\sim 16,500 \mathrm{Da}$ ) [3]. The agent is said to act by hydroflotation over several days, thus preventing contact between organs and traumatised tissue and thus adhesions are unable to form [3].

The aim of this review was to evaluate the efficacy of $4 \%$ icodextrin solution in the prevention of adhesion formation after fertility-conserving gynaecological surgery.

\section{Methods}

MEDLINE, EMBASE, CINAHL, PsychINFO and the Cochrane Menstrual Disorders and Subfertility Group Specialised Register of controlled trials were searched using the keywords: adhesion(s), adhesion barrier(s), adhesion prevention, gynaecological, pelvic, adept, and icodextrin. The reference lists of published papers were crosschecked. Studies published up to February 2012 were considered for inclusion. Randomised controlled trials (RCTs) which investigated the efficacy of $4 \%$ icodextrin solution as an anti-adhesion agent in gynaecological surgery were included. The surgery was fertility-conserving and may have either been performed by laparoscopy or laparotomy, on women of any age. Studies involving non-gynaecological surgery were excluded. There was no restriction on language. Two authors (FM and GA) independently assessed the suitability of the trials for inclusion. Any disagreements

Table 1 Characteristics of the included randomised controlled trials on the efficacy of $4 \%$ icodextrin solution on the prevention of adhesion formation in gynaecological surgery

\begin{tabular}{|c|c|c|c|}
\hline Study & Brown et al. [1] & diZerega et al. [3] & Trew et al. [5] \\
\hline Patients analysed $(n)$ & 402 & 53 & 330 \\
\hline Indication for surgery & $\begin{array}{l}\text { Planned laparoscopic } \\
\text { gynaecological surgery } \\
\text { which included } \\
\text { adhesiolysis }\end{array}$ & $\begin{array}{l}\text { Planned laparoscopic } \\
\text { gynaecological surgery } \\
\text { for pelvic pain and/or } \\
\text { infertility problems }\end{array}$ & $\begin{array}{l}\text { Planned laparoscopic gynaecological surgery for } \\
\text { primary removal of myomas or endometriotic } \\
\text { cysts. ( } \leq 4 \text { myomas and largest myoma } 2-8 \mathrm{~cm} \text { in diameter, } \\
\text { endometriotic cysts } 3-7 \mathrm{~cm} \text { in diameter) }\end{array}$ \\
\hline Inclusion criteria & \multicolumn{3}{|c|}{$\begin{array}{l}\text { All participants were } \geq 18 \text { years old, in good general health and undergoing laparoscopic gynaecological surgery only. } \\
\text { SLL performed } 4-16 \text { weeks after initial procedure }\end{array}$} \\
\hline $\begin{array}{l}\text { Exclusion criteria } \\
\text { (common) }\end{array}$ & \multicolumn{3}{|c|}{$\begin{array}{l}\text { Pregnancy, active pelvic/abdominal infection, known allergy to study materials, non-gynaecological procedures to be } \\
\text { performed during surgery, cancer, and concomitant use of steroids/antineoplastics/radiation }\end{array}$} \\
\hline $\begin{array}{l}\text { Exclusion criteria } \\
\text { (unique) }\end{array}$ & $\begin{array}{l}<3 \text { available anatomical } \\
\text { study sites with } \\
\text { adhesions, or }<3 \\
\text { sites lysed. }\end{array}$ & $\begin{array}{l}\text { More than half available } \\
\text { anatomical study sites } \\
\text { contained adhesions. }\end{array}$ & $\begin{array}{l}\text { Conversion to laparotomy, mAFS adhesion } \\
\text { score moderate or severe, AFS endometriosis } \\
\text { class III or IV (excluding cysts), or adhesions } \\
\text { which required lysing }\end{array}$ \\
\hline $\begin{array}{l}\text { Time of SLL after initial } \\
\text { procedure (weeks) }\end{array}$ & $4-8$ & $6-12$ & $4-16$ \\
\hline Timing of randomisation & Intraoperatively & Recruitment & $24 \mathrm{~h}$ prior to surgery \\
\hline Method of randomisation & Computer generated & $\begin{array}{l}\text { Envelope used, } \\
\text { no more information } \\
\text { given }\end{array}$ & Telephone randomisation \\
\hline Single or multicentre $(n)$ & Multicentre (16) & Multicentre (not known) & Multicentre (25) \\
\hline Presence of blinding & $\begin{array}{l}\text { Double-blinded } \\
\text { (patient and assessor) }\end{array}$ & Single-blinded (surgeon) & Double-blinded (patient and assessor) \\
\hline $\begin{array}{l}\text { Use of independent } \\
\text { blinded assessor }\end{array}$ & Yes & Yes & Yes \\
\hline $\begin{array}{l}\text { Presence of power } \\
\text { calculation }\end{array}$ & No & No & Yes \\
\hline $\begin{array}{l}\text { Was analysis intention to } \\
\text { treat? }\end{array}$ & Yes & Yes & Yes \\
\hline $\begin{array}{l}\text { Timing and location of } \\
\text { trial }\end{array}$ & $\begin{array}{l}\text { July 2001-March } 2004 \\
\text { USA }\end{array}$ & Not known USA & September 2003-August 2005 Europe \\
\hline Sources of funding & $\begin{array}{l}\text { Innovata Ltd, } \\
\text { Vectura Group }\end{array}$ & $\begin{array}{l}\text { No sources of funding } \\
\text { stated }\end{array}$ & $\begin{array}{l}\text { Shire Pharmaceutical Development Ltd, } \\
\text { Baxter BioSurgery }\end{array}$ \\
\hline
\end{tabular}

SLL second-look laparoscopy, $m A F S$ modified American Fertility Society, AFS American Fertility Society 
were settled by consensus with a third author (AW). The outcomes of the review were all related to the adhesions found at second-look laparoscopy (SLL). Specifically, these were: changes in severity of pelvic pain, pregnancy rate, incidence of adhesions, number of patients free from de novo adhesions, adhesion score, adhesion score reduction at SLL compared with initial laparoscopy, mean percentage reduction in the extent of adhesions, mean percentage reduction in the severity of adhesions and improvement or worsening in adhesion score.

The quality of the studies was evaluated, including: the timing and method of randomisation, whether it was a single or multicentre trial, the presence of blinding, the number of patients who were analysed, the presence of a power calculation, whether analysis was by intention to treat, the timing and location of the trial, and any sources of funding.

Data were input and analysed using Metaview of Review Manager (RevMan; RevMan version 5.2 Copenhagen: The Nordic Cochrane Centre, The Cochrane Collaboration, 2011). Dichotomous data (e.g. the number of patients free from de novo adhesions, and improvement or worsening of adhesion score) were expressed as an odds ratio (OR) with $95 \%$ confidence intervals (CIs). Continuous data (e.g. adhesion score at SLL, mean adhesion score reduction, mean percentage reduction in extent and severity) were presented as the mean difference (MD) with $95 \%$ CIs. The mean adhesion score reduction in DiZerega et al. [3] was calculated by subtracting the mean baseline adhesion score from the mean adhesion score at SLL, the standard deviation was calculated by assuming a within-patient correlation of 0.5 to calculate the variance of the mean reduction. It has been suggested that plausible values for the within-patient correlation could be in the range of $0.5-0.7$ [4]. Sensitivity to the assumed correlation was checked and the conclusions were unchanged. Meta-analysis was performed assuming a random effects model (DerSimonian-Laird). Results were considered statistically significant when $p<0.05$.

\section{Findings}

The initial search revealed 45 studies, three of which were eligible for inclusion, with a total of 785 participants $[1,3$, 5] (see Table 1). All three studies compared $4 \%$ icodextrin solution with Ringer's lactated saline (RLS) as the control. The administration of the agent was the same in the three studies: the abdomen was irrigated with $>100 \mathrm{ml}$ of agent every $30 \mathrm{~min}$ and $1,000 \mathrm{ml}$ instilled at the end, although DiZerega et al. instilled $400-1,000 \mathrm{ml}$ of RLS at the end of the procedure. The modified American Fertility Society (mAFS) adhesion scoring system was used by all the studies
Table 2 Efficacy of $4 \%$ icodextrin solution on the prevention of adhesion formation in gynaecological surgery

\begin{tabular}{|c|c|}
\hline Study & Adhesions at SLL \\
\hline Brown et al. [1] & $\begin{array}{l}\text { Number of patients free from de novo adhesions: } \\
\text { OR } 1.49[1.01,2.21] \\
\text { Adhesion score at SLL: } \\
\text { outcome not analysed } \\
\text { Adhesion score reduction at SLL: } \\
\text { MD } 1.51[0.322 .70] \\
\text { Mean \% reduction in extent of adhesions: } \\
\text { MD } 5.10[-4.67,14.87] \\
\text { Mean \% reduction in severity of adhesions: } \\
\text { MD } 2.70[-5.73,11.13] \\
\text { Improvement in adhesion score: } \\
\text { outcome not analysed } \\
\text { Worsening in adhesion score: } \\
\text { outcome not analysed }\end{array}$ \\
\hline diZerega et al. [3] & $\begin{array}{l}\text { Number of patients free from de novo adhesions: } \\
\text { outcome not analysed } \\
\text { Adhesion score at SLL: } \\
\text { outcome not analysed } \\
\text { Adhesion score reduction at } \mathrm{SLL}^{\mathrm{a}} \text { : } \\
\text { MD } 0.10[-0.50,0.70] \\
\text { Mean \% reduction in extent of adhesions: } \\
\text { MD } 21.00[-42.36,84.36] \\
\text { Mean \% reduction in severity of adhesions: } \\
\text { MD } 47.00[-15.76,109.76] \\
\text { Improvement in adhesion score: } \\
\text { OR } 3.24[0.86,12.12] \\
\text { Worsening in adhesion score: } \\
\text { OR } 0.28[0.07,1.21]\end{array}$ \\
\hline
\end{tabular}

Trew et al. [5] Number of patients free from de novo adhesions: OR $0.92[0.55,1.54]$

Adhesion score at SLL:

MD -0.29 [-2.97, 2.39]

Adhesion score reduction at SLL:

outcome not analysed

Mean \% reduction in extent of adhesions:

outcome not analysed

Mean \% reduction in severity of adhesions:

outcome not analysed

Improvement in adhesion score:

outcome not analysed

Worsening in adhesion score:

outcome not analysed

$S L L$ second-look laparoscopy, $O R$ odds ratio, $M D$ mean difference, $S D$ standard deviation

${ }^{\text {a }}$ Calculated by subtracting the mean score at SLL from the mean baseline score. SD calculated by assuming a within-patient correlation of 0.5 for the sensitivity analysis 
a Number of patients free of de novo adhesions

\begin{tabular}{lrcrrrr} 
Study & \multicolumn{2}{c}{ 4\% icodextrin } & \multicolumn{2}{c}{$\begin{array}{c}\text { Ringer's-Lactated Saline } \\
\text { (RLS) }\end{array}$} & $\begin{array}{c}\text { Weight } \\
(\%)\end{array}$ & Odds Ratio \\
& $\begin{array}{c}\text { Patients free } \\
\text { of de novo } \\
\text { adhesions }\end{array}$ & $\begin{array}{c}\text { Total } \\
\text { number of } \\
\text { patients }\end{array}$ & $\begin{array}{c}\text { Patients free } \\
\text { of de novo } \\
\text { adhesions }\end{array}$ & $\begin{array}{c}\text { Total } \\
\text { number of } \\
\text { patients }\end{array}$ & $\begin{array}{c}\text { M-H, Random, } \\
\mathbf{9 5 \%} \text { CI }\end{array}$ \\
\hline Brown 2007 & 108 & 203 & 86 & 199 & 56.1 & $1.49[1.01,2.21]$ \\
Trew 2011 & 38 & 170 & 38 & 160 & 43.9 & $0.92[0.55,1.54]$ \\
Total (95\% CI) & & $\mathbf{3 7 3}$ & & $\mathbf{3 5 9}$ & $\mathbf{1 0 0 . 0}$ & $\mathbf{1 . 2 1}[\mathbf{0 . 7 6 , 1 . 9 3 ]}$
\end{tabular}

Heterogeneity: $\mathrm{Tau}^{2}=0.06 ; \mathrm{Chi}^{2}=2.12, \mathrm{df}=1(\mathrm{P}=0.15) ; \mathrm{I}^{2}=53 \%$

Test for overall effect: $\mathrm{Z}=0.80(\mathrm{P}=0.42)$

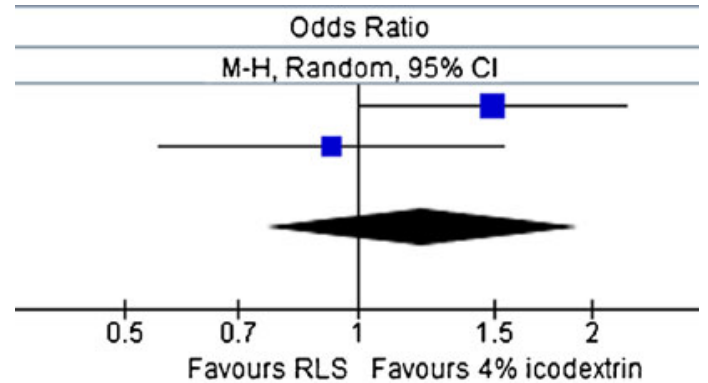

b Mean reduction in mAFS score per patient -0.5 variance

\begin{tabular}{|c|c|c|c|c|c|c|}
\hline \multirow[t]{2}{*}{ Study } & \multicolumn{2}{|c|}{$4 \%$ icodextrin } & \multicolumn{2}{|c|}{$\begin{array}{c}\text { Ringer's-Lactated Saline } \\
\text { (RLS) }\end{array}$} & \multirow[t]{2}{*}{$\begin{array}{l}\text { Weight } \\
(\%)\end{array}$} & \multirow{2}{*}{$\begin{array}{l}\text { Mean difference } \\
\text { IV, Random, } \\
\text { 95\% CI }\end{array}$} \\
\hline & Mean (SD) & $\begin{array}{c}\text { Total } \\
\text { number of } \\
\text { patients }\end{array}$ & Mean (SD) & $\begin{array}{c}\text { Total } \\
\text { number of } \\
\text { patients }\end{array}$ & & \\
\hline Brown 2007 & $2.7(6.18)$ & 203 & $1.19(5.98)$ & 199 & 43.1 & $1.51[0.32,2.70]$ \\
\hline diZerega 2002 & 0.19 (1.27) & 23 & $0.09(0.69)$ & 19 & 56.9 & $0.10[-0.50,0.70]$ \\
\hline Total $(95 \%$ CI) & & 226 & & 218 & 100.0 & $0.71[-0.66,2.08]$ \\
\hline
\end{tabular}

Heterogeneity: $\mathrm{Tau}^{2}=0.76 ; \mathrm{Chi}^{2}=4.29, \mathrm{df}=1(\mathrm{P}=0.04) ; \mathrm{I}^{2}=77 \%$

Test for overall effect: $\mathrm{Z}=1.01(\mathrm{P}=0.31)$

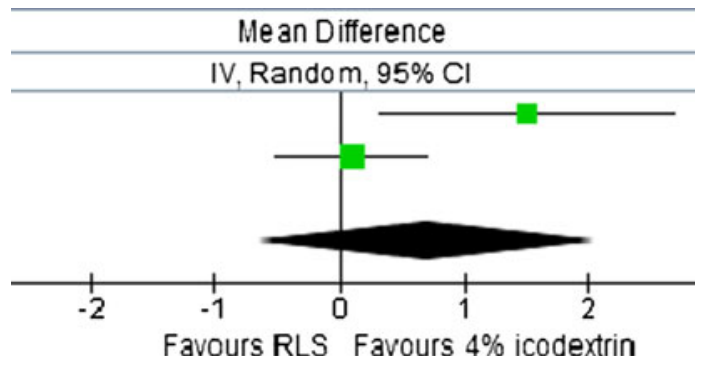

Fig. 1 Meta-analyses of adhesions at second-look laparoscopy. a Number of patients free from de novo adhesions. b Mean reduction in mAFS score per patient, 0.5 variance. $\mathbf{c}$ Mean percent reduction in

which assesses the incidence, extent and severity of adhesions at 23 specified anatomical sites. None of the included studies provided data on the outcomes of the pregnancy rate, or the incidence of adhesions at SLL. Brown et al. found that in the patients with a primary diagnosis of pelvic pain, 118/ extent of adhesions per patient. $\mathbf{d}$ Mean percent reduction in severity of adhesions per patient. $m A F S$ modified American Fertility Society, $S D$ standard deviation, $C I$ confidence interval

$152(83 \%)$ patients treated with $4 \%$ icodextrin solution demonstrated a clinically significant decrease in pelvic pain, compared to 108/134 (82\%) of patients who received RLS. None of the outcomes were reported by all three studies (see Table 2). 
c Mean \% reduction in extent of adhesions per patient

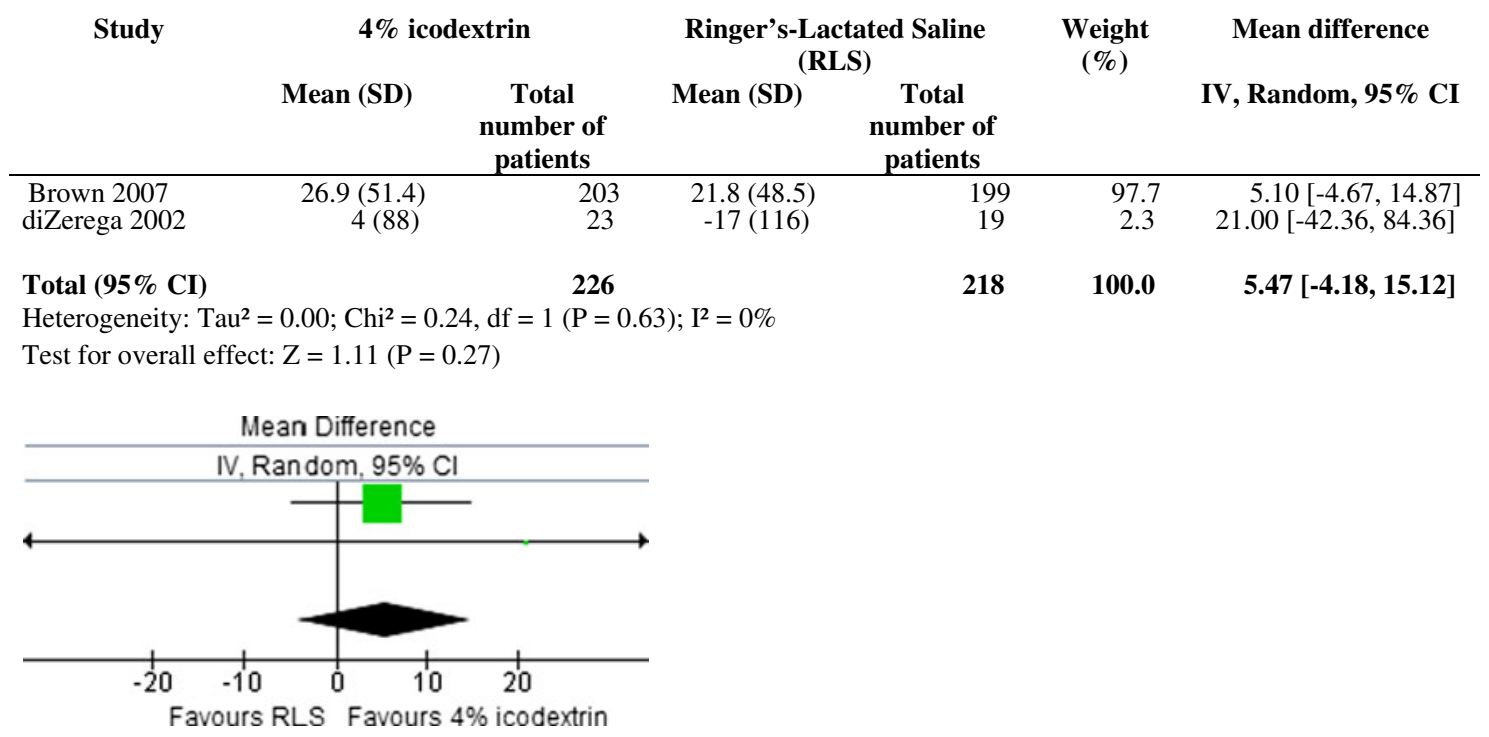

d Mean \% reduction in severity of adhesions per patient

\begin{tabular}{|c|c|c|c|c|c|c|}
\hline \multirow[t]{2}{*}{ Study } & \multicolumn{2}{|c|}{$4 \%$ icodextrin } & \multicolumn{2}{|c|}{$\begin{array}{l}\text { Ringer's-Lactated Saline } \\
\text { (RLS) }\end{array}$} & \multirow[t]{2}{*}{$\begin{array}{c}\text { Weight } \\
(\%)\end{array}$} & \multirow{2}{*}{$\begin{array}{c}\text { Mean difference } \\
\text { IV, Random, } 95 \% \text { CI }\end{array}$} \\
\hline & Mean (SD) & $\begin{array}{c}\text { Total } \\
\text { number of } \\
\text { patients }\end{array}$ & Mean (SD) & $\begin{array}{c}\text { Total } \\
\text { number of } \\
\text { patients }\end{array}$ & & \\
\hline Brown 2007 & $24.2(45.2)$ & 203 & $21.5(41)$ & 199 & 75.6 & $2.70[-5.73,11.13]$ \\
\hline diZerega 2002 & $21(82)$ & 23 & $-26(118)$ & 19 & 24.4 & $47.00[-15.76,109.76]$ \\
\hline Total $(95 \%$ CI $)$ & & 226 & & 218 & 100.0 & $13.49[-23.78,50.75]$ \\
\hline \multicolumn{7}{|c|}{ Heterogeneity: $\mathrm{Tau}^{2}=459.39 ; \mathrm{Chi}^{2}=1.88, \mathrm{df}=1(\mathrm{P}=0.17) ; \mathrm{I}^{2}=47 \%$} \\
\hline \multicolumn{7}{|c|}{ Test for overall effect: $\mathrm{Z}=0.71(\mathrm{P}=0.48)$} \\
\hline \multicolumn{7}{|c|}{ Mean Difference } \\
\hline \multirow{2}{*}{\multicolumn{7}{|c|}{ IV, Random, $95 \% \mathrm{Cl}$}} \\
\hline & & & & & & \\
\hline-100 & & 50 & 100 & & & \\
\hline
\end{tabular}

Fig. 1 (continued)

Meta-analysis of Brown et al. and Trew et al. showed a nonstatistically significant reduction in the number of patients free from de novo adhesions with $4 \%$ icodextrin when compared to patients who received RLS (OR 1.21 [0.76, 1.93]) (see Figure 1). The mean adhesion score reduction per patient at SLL which was reported by Brown et al. and diZerega et al. was not statistically significant (MD $0.71[-0.66,2.08])$. Nor was the meta-analysis of the mean percentage reduction in the extent of adhesions (MD $5.47[-4.18,15.12])$, or the severity of adhesions (MD 13.49 [-23.78, 50.75]) which were both investigated by Brown et al. and diZerega et al. The remainder of the outcomes, i.e. the adhesion score at SLL and improvement or worsening in adhesion score between first-look laparoscopy and SLL, were explored by individual studies, which found no significant difference between $4 \%$ icodextrin solution and RLS (see Table 2).

\section{Conclusions}

This review failed to demonstrate the effectiveness of $4 \%$ icodextrin in preventing adhesions after pelvic surgery. The three studies included presented data relating to the adhesion score at SLL, but they all used different actual outcomes. Because of this no meta-analysis used data from more than two studies.

One issue this review has raised is the low number of RCTs which have been conducted on $4 \%$ icodextrin 
solution in gynaecological surgery, despite its widespread use. Another issue was the different ways the authors reported the effect of $4 \%$ icodextrin solution on adhesions. Out of the eight different measurements of adhesions at SLL which were analysed, none were reported by all three studies. Although the three studies used the mAFS adhesion score, often different aspects were reported. For example, it was not possible to analyse the incidence of adhesions at SLL as Brown et al. stated the reduction in the number of sites of adhesions at SLL but did not provide the number of adhesion sites at baseline, whereas DiZerega et al. reported the incidence of adhesions in patients with at least one adhesion at baseline, and Trew et al. reported only the incidence of de novo adhesions. There was also no longterm follow-up with contact terminating after SLL and the longest time between the initial laparoscopy and the SLL being 16 weeks. It would be interesting to see if there was any difference in the safety/adverse events such as bowel obstruction with further follow up.

This is the first meta-analysis of the efficacy of $4 \%$ icodextrin solution as an adhesion prevention agent in gynaecological surgery to the authors' knowledge. It has demonstrated that there is a dearth of evidence regarding the use of $4 \%$ icodextrin solution. The findings suggest that currently, there is insufficient evidence to support that $4 \%$ icodextrin solution is effective at preventing adhesions in gynaecological surgery compared to RLS. Although $4 \%$ icodextrin solution is cheaper and easier toapply than other commercial adhesion-prevention agents, if it does not prevent adhesions it is neither in the patient's best interest, or cost-effective to continue using it. The American Society for Reproductive Medicine recommends that the mAFS score should be used when evaluating adhesion prevention agents; however in addition to this, data should be published in complete and in a way which allows for comparison with other studies. Alternative adhesion prevention agents should continue to be considered for gynaecological surgery.

This review does not support the use of $4 \%$ icodextrin solution as an anti-adhesion agent in gynaecological surgery. More research is required into adhesion prevention agents, the results of which should be reported in a uniform manner to enable comparison.

Acknowledgments The Cochrane Menstrual Disorders and Subfertility Group, Department of Obstetrics and Gynaecology, University of Auckland, Auckland, New Zealand who helped with the search for relevant studies, particularly Marian Showell.

Declaration of interest Dr. Watson received consultancy and lecture fees in 2003 from Shire Pharmaceuticals. Dr. Watson has received lecture fees from Gynaecare, Shire and Baxter all of whom distributed adhesion prevention modalities when the lecture on adhesion prevention was given. In addition he received a consultancy fee from Shire when the use of icodextrin to prevent adhesions was first being promoted. The other authors report no conflicts of interest. The authors alone are responsible for the content and writing of the paper.

\section{Reference list}

1. Brown C, Luciano A, Martin D, Peers E, Scrimgeour A, DiZerega G (2007) Adept (icodextrin 4\% solution) reduces adhesions after laparoscopic surgery for adhesiolysis: a double-blind, randomized, controlled study. Fertil Steril 88:1413-1426

2. Diamond M, Freeman M (2001) Clinical implications of postsurgical adhesions. Hum Reprod Update 7:567-576

3. diZerega G, Verco S, Young P, Kettel M, Kobak W, Martin D et al (2002) A randomized, controlled pilot study of the safety and efficacy of $4 \%$ icodextrin solution in the reduction of adhesions following laparoscopic gynaecological surgery. Human Reprod 17:1031-1038

4. Frison L, Pocock S (1992) Repeated measures in clinical trials: analysis using mean summary statistics and its implications for design. Stat Med 11:1685-1704

5. Trew G, Pistofidis G, Pados G, Lower AM, Mettler L, Wallwiener $\mathrm{D}$ et al (2011) Gynaecological endoscopic evaluation of $4 \%$ icodextrin solution: a European, multicentre, double-blind, randomized study of the efficacy and safety in the reduction of de novo adhesions after laparoscopic gynaecological surgery. Human Reprod 26:2015-2027

6. Wilson M, Menzies D, Knight A, Crowe A (2002) Demonstrating the clinical and cost effectiveness of adhesion reduction strategies. Colorec Dis 4:355-360 